
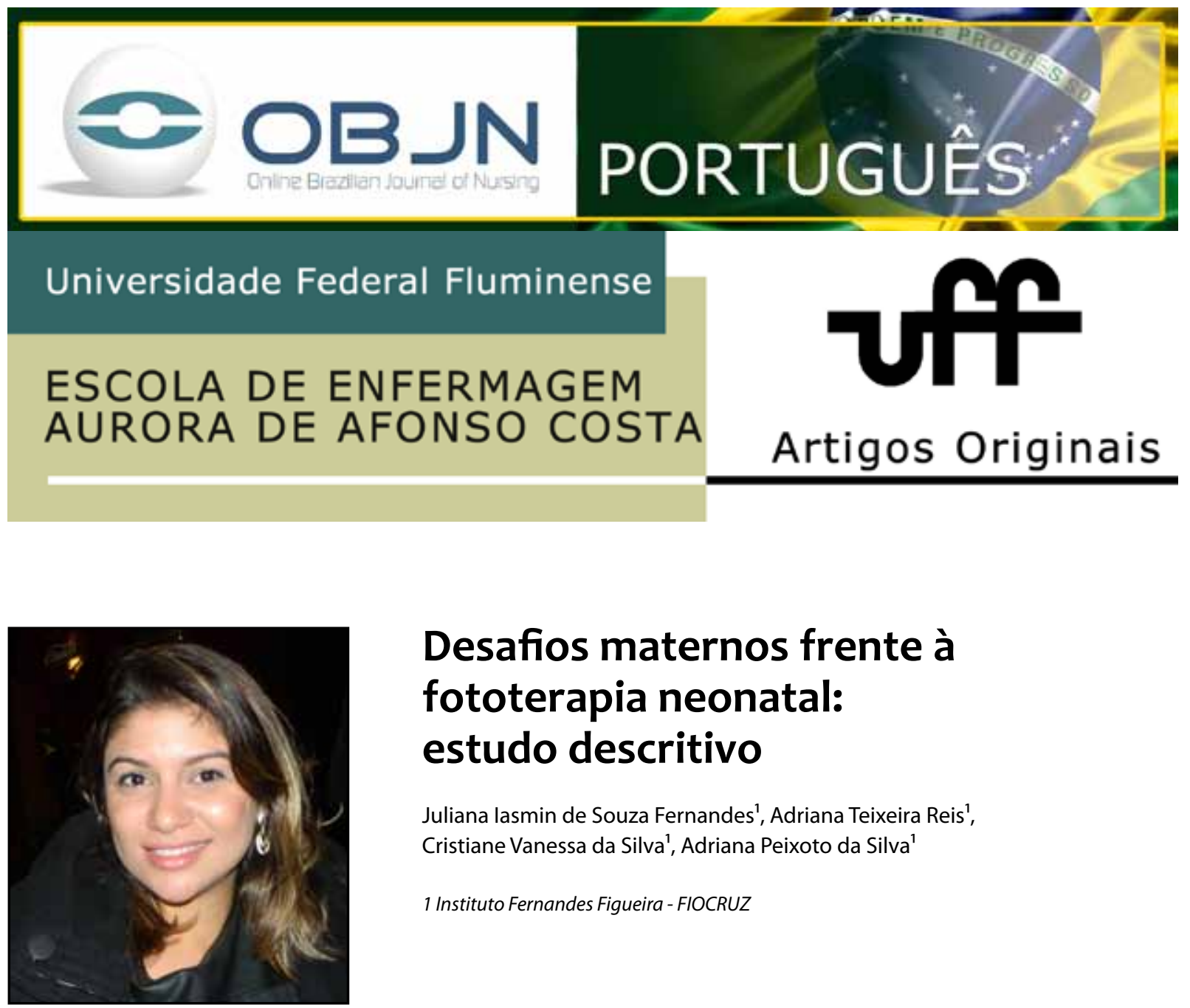

\title{
Desafios maternos frente à fototerapia neonatal: estudo descritivo
}

\author{
Juliana lasmin de Souza Fernandes ${ }^{1}$, Adriana Teixeira Reis', \\ Cristiane Vanessa da Silva', Adriana Peixoto da Silva ${ }^{1}$ \\ 1 Instituto Fernandes Figueira - FIOCRUZ
}

\section{RESUMO}

Objetivo: revelar os desafios enfrentados por mães de recém-nascidos submetidos ao tratamento de fototerapia neonatal em alojamento conjunto. Método: estudo descritivo, com abordagem qualitativa, realizado por meio de entrevista com 10 mães que vivenciaram o tratamento de fototerapia neonatal no alojamento conjunto, no período de junho a outubro de 2014, em uma instituição pública da cidade do Rio de Janeiro. Os dados foram alicerçados na análise de conteúdo de Bardin. Resultado: emergiram três categorias analíticas: Sentimentos e Reações das mães frente ao tratamento fototerápico; $O$ desconhecimento frente a uma nova realidade e $A$ equipe como rede de apoio às mães. Discussão: Apesar de o tratamento fototerápico ser simples, ele gera para as mães muitas dúvidas e sentimentos negativos de angústia, tristeza e culpa. Conclusão: A equipe de enfermagem deve estar sensível a ouvir e orientar as mães diante da fototerapia, considerando que é uma vivência adversa durante a internação do recém-nascido.

Descritores: Recém-nascido; Hiperbilirrubinemia; Fototerapia; Enfermagem Neonatal. 


\section{INTRODUÇÃO}

A hiperbilirrubinemia neonatal, conhecida popularmente como icterícia, é um achado físico associado a múltiplas etiologias ${ }^{(1,2)}$. Causada por um nível elevado de bilirrubina no sangue, caracteriza-se por apresentar uma pigmentação amarelo-laranja na pele, esclera e outros teci$\operatorname{dos}^{(1,3)}$. Resultada da imaturidade das funções do fígado combinada com a destruição das hemácias no recém-nascido $(\mathrm{RN})^{(4,3)}$. Estima-se que cerca de $60 \%$ dos recém-nascidos a termo (RNT) e $80 \%$ dos recém-nascidos pré-termo (RNPT) apresentam algum grau de hiperbilirrubinemia nos primeiros dias de vida ${ }^{(5)}$.

A icterícia é classificada em fisiológica ou patológica, porém em metade dos casos sua origem é fisiológica e normalmente apresenta-se de forma leve e com regressão espontânea. Quando não há regressão espontânea ou existe a suspeita em ser patológica, o RN é submetido a tratamentos, dentre eles a fototerapia ${ }^{(1,3)}$. A fototerapia utiliza equipamentos providos de luz florescente e halógena, a fim de eliminar a bilirrubina pela urina e fezes, por meio de mecanismos de fotoisomerização e foto-oxidação $(1,6)$.Trata-se de um método não invasivo e de alto impacto na diminuição dos níveis de bilirrubina, independente da maturidade do $\mathrm{RN}^{(7)}$.

O tratamento fototerápico, quando instituído no Alojamento Conjunto (AC), utiliza geralmente equipamentos como biliberço e bilispot, tendo em vista que equipamentos mais modernos, na realidade brasileira, são utilizados em contexto da terapia intensiva neonatal pela sua maior complexidade de manejo e pelos efeitos adversos quais os profissionais de saúde ficam expostos, como tonteira e náuseas ${ }^{(6)}$. Para as famílias, em particular às mães que acompanham seus filhos em AC, torna-se uma situação inusitada, pois grande parte dos $\mathrm{RN}$ recebem cuidados básicos, não sendo comum a utilização de maiores tecnologias neste contexto. Destacam-se neste espaço a orientação e o incentivo materno para a realização dos cuidados, a fim de preparar a mãe para alta, bem como fortalecer e estreitar a relação do binômio mãe-bebê.

Dessa forma, este estudo objetivou revelar os desafios enfrentados por mães de RN submetidos ao tratamento de fototerapia em AC.

\section{MÉTODO}

Trata-se de um estudo descritivo, com abordagem qualitativa ${ }^{(8,9)}$. O cenário foi o $A C$ de um hospital público federal, situado no município do Rio de Janeiro, de nível terciário, com título de Amigo da Criança, sendo referência no tratamento de $\mathrm{RN}$ de alto risco.

O cenário de estudo dispõe de 19 leitos divididos em boxes duplos, permitindo a acomodação de um berço comum ao lado do leito de puérpera. Neste setor os $\mathrm{RN}$ recebem cuidados diretos de suas mães, sendo supervisionados pela equipe de enfermagem. Sempre que um RN necessita de fototerapia, a equipe de enfermagem busca acomodar esse binômio em box único.

A coleta de dados ocorreu no período de junho a outubro de 2014, com participação de 10 mães de RN submetidos ao tratamento fototerápico em AC e que aceitaram participar por meio da assinatura do Termo de Consentimento Livre e Esclarecido (TCLE). Foram excluídas do estudo as mães que não estavam em condições físicas e/ou psíquicas no momento da coleta de dados.

Utilizou-se como instrumento de coleta de dados um roteiro para entrevista semiestruturada que constou de duas partes, sendo a primeira com dados sociodemográficos e obstétricos ${ }^{(10)}$. A segunda referiu-se às questões norteadoras da entrevista: como foi para você saber que seu filho necessitaria realizar fototerapia? Qual é o 
seu sentimento ao presenciar o dia a dia de seu bebê em fototerapia? Os depoimentos foram gravados e, posteriormente, transcritos.

A coleta de dados encerrou-se quando foi obtido o ponto de saturação nos depoimentos $^{(11)}$. Para garantir o anonimato das participantes, sua identificação se deu por meio de numeração de acordo com a ordem em que foram realizadas as entrevistas - por exemplo: entrevistada 1.

Para a compreensão das narrativas, foi utilizada a análise temática de Bardin ${ }^{(12)}$. Formaram-se três categorias analíticas: Sentimentos e Reações das mães ao tratamento; O desconhecimento frente a uma nova realidade e A equipe como rede de apoio às mães.

Após a categorização, realizou-se o confronto com a literatura científica. Para isso foi feita a busca de artigos científicos por meio de base de dados: Literatura Latino-Americana e do Caribe em Ciências da Saúde (LILACS), Medical Literature Analysis and Retrieval System Online (MEDLINE), Scientific Eletronic Library Online (SciELO) e Base de Dados de Enfermagem (BDENF).

O estudo obedeceu os preceitos éticos estabelecidos pela Resolução n 466/2012 do Conselho Nacional de Saúde (CNS) ${ }^{(13)}$. O projeto obteve aprovação pelo Comitê de Ética em Pesquisa da instituição, sob número 819.980/2014.

\section{RESULTADOS}

Do grupo de 10 mães, a média da idade foi de 32,7 anos, com desvio padrão (DP) de $\pm 12,7$. Quanto ao número de gestações, quatro eram primíparas e seis multíparas. Quanto ao tipo de parto, cinco tiveram parto normal. No que tange à escolaridade materna, foram identificadas uma mãe com pós-graduação, sete com ensino médio completo, uma com ensino médio incom- pleto, uma com ensino fundamental completo. Verificou-se que todas as participantes realizaram mais de seis consultas de pré-natal.

A idade gestacional (IG) média dos RN foi de 38,6 com desvio padrão (DP) de $\pm 2,5$. No momento da entrevista, os RN tinham entre dois e sete dias de idade cronológica, com desvio padrão (DP) de $\pm 2,5$.

Apenas uma participante estava vivenciando o tratamento pela segunda vez.

Categoria 1: Sentimentos e reações das mães ao tratamento fototerápico

Esta categoria correspondeu a 44,29\% das unidades de registro (UR), representando 163 UR de um total de 368 UR e nove unidades de significação (US).

Para as mães, as reações presentes diante da fototerapia correspondem a sentimentos mistos e antagônicos. Por ser uma situação que foge do curso esperado por elas, suscita dor, tristeza, preocupação, culpa e sentimento de postergação da ida para casa. Evidenciam-se tais sentimentos nas falas a seguir:

[...] mas só a fototerapia é muito doloroso [...] (Entrevista 2)

[...] Ah, horrível! Eu só chorei, porque ficar vendo ali ele daquele jeito chorando. Aí eu perguntei se a gente podia pegar, a princípio falou que não podia pegar [...] Ele chora eu choro, ontem entrei em crise, peguei na mãozinha dele e chorei tanto, tanto (choro) É muito ruim... (choro) E eu tenho outra filha, é muito difícil ficar entre dois [...] (Entrevista 3)

[...] Ah, fiquei triste! Ah, fiquei preocupada! Ah, fiquei pensando assim se 
a culpa era minha, me culpando, foi isso, mas depois passou. Agora já reagi melhor [...] (Entrevista 5)

Entretanto, ainda conseguem preservar sentimentos de esperança e resiliência:

[...] Ah, o sentimento que ela ficasse boa logo e não precisasse ficar tanto tempo fazendo. Não fiquei com sentimento assim depressivo não, fiquei mais com sentimento de vai funcionar, vai dar tudo certo, vai melhorar, pensamento positivo! [...] (Entrevista 9)

\section{Categoria 2: O desconhecimento frente a uma nova realidade}

É formada por três US e cinco UR, sendo elas dúvida, (des) conhecimento, falta de orientação ao tratamento, "pega de surpresa" e falta de clareza nas informações, totalizando 151 UR, que representam 41,03\% da categoria.

Ao vivenciar esta situação, as mulheres acabam criando pensamentos fantasiosos sobre a situação de saúde dos seus filhos, frente ao tratamento e à patologia. Tantas dúvidas e medos podem ser consequências de falha no processo de comunicação entre as mães e a equipe de saúde. Tais dúvidas são exemplificadas nos trechos a seguir:

[...] Aí eu não sei se está queimando, eu não sei se pode trazer algum dano pra pele, não sei se vai descascar depois, se queima, se ele vai ficar ardido [...] Será que ele vai ficar muito moreno de um lado e do outro não? Principalmente aquele colchãozinho; se aquilo é confortável, está muito duro? Eu fico pensando'será que está machucando?' [...] (Entrevista 2)
[...] Sinceramente, para uma pessoa assim como eu, totalmente desinformada a respeito, podia ser mais explicado assim, numa linguagem mais simples, podia informar o que é. Eu não sei se é um vírus, se é uma bactéria, o que que é esse negócio de icterícia (risos), sinceramente, por que que está ali, não sei, sabe? [...] (Entrevista 7)

O desconhecimento destas mulheres sobre o tratamento ao qual seus filhos são submetidos suscita nelas pensamentos arraigados de experiências culturais e saberes populares:

[...] assim, pelo conhecimento que tenho dos antigos, quando nasce assim amarelinho, toma banho de sol e chá de picão e tudo se resolve, né? Então eu achei normal. [...] Mas eu não sabia que era tão grave assim, que poderia haver várias consequências [...] Você não entende e não sabe e recebe isso de uma maneira assim, te assusta muito, você fica com muito medo [...] No primeiro dia [...] essa menina disparou a fazer cocô, um atrás do outro. E eu me desesperei, eu disse 'será que ela está sentindo dor? Ela está enjoadinha?' [...] (Entrevista 10)

Categoria 3: a equipe como rede de apoio às mães

Foi expressa por uma US (o apoio da equipe), totalizando 54 UR, ou $14,67 \%$ da categoria. Grande parte das mães relata ter recebido o apoio das equipes de saúde durante o tratamento fototerápico.

[...] Sempre tinha alguém reforçando os cuidados... Vinha enfermeiro, pediatra, 
passava para deixar o medicamento aí já falava [...] (Entrevista 1)

[...] Me apoiaram de início com os cuidados, as instruções dos cuidados e também com as explicações. O médico explicou direito o que eu tinha que fazer, como eu não tinha que fazer, então todos eles vieram e foram atenciosos. Eu tive dos enfermeiros no decorrer do dia, dia e noite, o tempo todo, todas as minhas dúvidas foram tiradas [...] (Entrevista 8)

Em contrapartida, algumas mães referiram a ausência desse apoio e ressaltam a não uniformidade na assistência prestada por parte da equipe, como pode-se observar nos trechos que se seguem:

[...] assim, a gente não sabe muito bem para quem perguntar. Tem enfermeira que é muito boa que a gente pergunta, mas tem enfermeira que elas não ligam [...] Não são todas que te dá a liberdade de você chegar para perguntar nada, então o apoio que a gente tem mesmo é da família [...] (Entrevista 3)

[...] eu não sabia explicar para ele (o pai), eu só disse para ele:'olha, ela (a médica) disse que tem que fazer isso aí porque a pele dela está ficando amarela [...] Aí só isso que eu pude falar pra ele. Aí eu pedi, fui ali pedir pra algum médico vir conversar com ele que ele queria entender [...] Você busca informação, você quer informação, você quer se sentir segura, [...] eu não sabia que o hospital fazia estes procedimentos, que tinha esse cuidado com o bebê [...] (Entrevista 10)
A equipe de enfermagem dispensa maior tempo com os cuidados ao binômio mãe-bebêe está mais presente no cotidiano destas famílias. Desta forma pode, além de outras categorias, ser um elemento essencial para garantia de diálogo e escuta sensível, a fim de promover espaços para resolução de dúvidas frente ao tratamento fototerápico.

Ao dar voz a estas mães, percebe-se que elas trazem propostas que podem nortear as ações de enfermagem na prática cotidiana:

[...] teria que ter um grupo de apoio para explicar o dia a dia. É difícil, porque você é pega de surpresa. Eu fiz o pré-natal aqui, até então na ultrassonografia estava dando tudo bem [...] Explicaram aqui que meu sangue não era compatível com o dele, por isso ela teria que passar pela fototerapia [...] (Entrevista 4)

\section{DISCUSSÃO}

As narrativas demonstram sentimentos negativos para as mães ao vivenciarem a necessidade do tratamento fototerápico de seu filho, uma vez que esta situação foge do curso esperado por elas.

Diante dos desafios enfrentados, a certeza de que o resultado do tratamento será o meIhor para seu filho faz com que os sentimentos de pesar, que permeiam seu cotidiano, sejam superados.

O tratamento gera medo e estresse nestas mulheres, pois eles se encontram fragilizadas e inseguras quanto à saúde de seu filho, desvelados por sentimentos ambivalentes como culpa, responsabilização pelo "sofrimento" do filho ao mesmo tempo em que também manifestam esperança e resignação ${ }^{(14)}$. 
Apesar de o tratamento ser bastante comum para os profissionais de saúde fazendo parte do cotidiano do AC, deve-se considerar que, para as mães, o tratamento se apresenta como algo diferente do esperado, desconhecido e, na maioria das vezes, assustador. $\mathrm{O}$ fato de ter um filho em fototerapia requer cuidados específicos, como manter o RN despido sob a luz o maior tempo possível e proteger os olhos com venda apropriada. Esses cuidados foram os que provocaram queixas das mães, além de alguns efeitos colaterais esperados como bronzeamento da pele e diarreia. Tudo isso pode despertar nas mães sentimentos de tristeza e ansiedade por não conhecerem e não compreenderem bem a proposta terapêutica ${ }^{(15)}$.

O processo de adaptação dessas mães parece receber influência de fatores externos como social, cultural e familiar. Suas histórias de vida e experiências pregressas refletem nos sentimentos e atitudes que variam de pessoa a pessoa. Agrega-se a isso a qualidade da assistência fornecida pela equipe e a forma como esta possibilita às mães a expressão de seus sentimentos ${ }^{(16)}$.

Estar próxima do RN e assistir lado a lado sua recuperação se configuram como fatores que favorecem a resiliência diante de situações adversas para que as mesmas possam se fortalecer e superar sentimentos negativos.

A orientação continuada desde o início até o término da terapia pode dirimir algumas dúvidas e pode ser ofertada por meio de uma linguagem de fácil compreensão. As informações dadas devem contemplar o que é fototerapia e quais serão os cuidados diários a serem tomados com o RN durante todo tratamento, ressaltando que ficará restrito pegá-lo sempre que desejar, vesti-lo e até mesmo manter um contato olho no olho(17).

A comunicação potencializa a relação entre profissionais de saúde e familiares, tornando a assistência mais humanizada, minimizando angústias e sentimentos de desvalia diante do tratamento. Uma assistência de qualidade não se limita somente a procedimentos técnicos, mas inclui relações humanas e diálogo, incluindo a percepção de mensagens não verbais e respeito às singularidades ${ }^{(18,19)}$.

A maioria das ações em saúde têm enfocado as tecnologias duras e leve-duras sobrepondo às tecnologias relacionais ou leves. A alta tecnologia, por vezes, impede um atendimento individualizado, o maior envolvimento da equipe e a humanização do cuidado(20).

No cenário deste estudo, as participantes encontravam-se frágeis, solitárias e sensíveis, passando a compartilhar esse momento com outras mães e tendo a necessidade de maior atenção da equipe. Para que se sintam institucionalmente acolhidas, atitudes de carinho, respeito, compreensão, atenção e resgatar o espaço de acolhimento, da escuta atenta e interessada focada nas necessidades e expectativas dessas mães pode fazer a diferença. Essa mudança de comportamento pode ser um estímulo à transformação das práticas em saúde, onde o saber clínico está associado às necessidades dos usuários $^{(21,22) .}$

Fortalecer o uso de tecnologias leves e uma escuta atenta são desafios no cotidiano da enfermagem neonatal. Entretanto, necessários para garantir a autonomia do usuário e respeitar sua condição de coparticipante do processo terapêutico. No contexto da assistência neonatal, a mãe (ou responsável) é a figura que negocia com as equipes de saúde aquilo que acredita ser melhor para o bebê, neste caso, seu filho. Portanto, dar-lhes voz torna-se uma ferramenta essencial na garantia de maior segurança e adesão à proposta terapêutica.

Reconhecer as necessidades não só do RN em fototerapia, mas também dúvidas e anseios maternos, pode ser uma ferramenta potencia- 
lizadora da força que ela busca para enfrentar um momento de fragilidade devido à saúde do seu filho.

\section{CONCLUSÃO}

A pesquisa evidenciou alguns desafios enfrentados pelas mães durante o tratamento fototerápico de seus filhos. Propiciou uma melhor compreensão sobre os sentimentos vivenciados diariamente por elas. Medo, dúvidas, tristeza, inquietações e falta de conhecimento sobre a patologia e tratamento estiveram presentes nas falas.

A comunicação efetiva foi apontada como um elemento a ser lembrado pelos profissionais de saúde durante o processo terapêutico. Trata-se de ferramenta essencial para um cuidado individualizado e fortalece a rede de apoio neste momento complexo na vida dessas famílias.

Tomou-se como limitação do estudo o fato de ter sido realizado em um único centro, merecendo novas investigações, a fim de tornar dados mais generalizáveis.

Por fim, o tratamento fototerápico apresentou-se como uma vivência complexa na vida destas mães, devendo ser mais bem explorado por meio de outras pesquisas que possam nortear melhorias nas ações da enfermagem neonatal.

\section{REFERÊNCIAS}

1. Cohen RS, Wong, RJ, Stevenson DK. Understanding neonatal jaundice: A perspective on causation. Pediatr Neonatol 2010.51(3): 143-148.

2. Ives NK. Management of neonatal jaundice. Pediatrics and child health 2011. 21(6): 270-277.

3. Araújo LA, Reis AT. Enfermagem na prática materno-neonatal. Rio de Janeiro: Guanabara Koogan; 2012. p.253.
4. Hansen TWR. Phototherapy for neonatal jaundice - therapeutic effects on more than one level? Seminars in perinatology. 2010. 34: 231-234.

5. Vaz FAC, Diniz EMA, Ceccon MEJR, Krebs VLJ. Pediatria - Instituto da Criança Hospital das clínicas - neonatologia. Barueri: Manole; 2011.p. 238.

6. Carvalho M. Tratamento de icterícia neonatal. Jornal de pediatria. 2001 Jul; p.s72.

7. Castro PS, Silva SMS, Linhares TRC, Sousa AM. O conhecimento das mães de recém-nascidos com icterícia neonatal sobre o tratamento fototerápico. Revista Interdisciplinar NOVAFAPI [internet] 2012 Jan-Fev-Mar; [citaed 2014 ago 10 ] 5(1). Available from: http://www.novafapi.com.br/ sistemas/revistainterdisciplinar/v5n1/pesquisa/ p2_v5n1.pdf

8. Andrade MM. Introdução à Metodologia do Trabalho Científico. 5 a ed. São Paulo: Atlas; 2001.

9. Minayo MCS. Pesquisa social: teoria, método e criatividade. 20a ed. Petrópolis: Vozes; 2002.

10. Marconi MA, Lakatos ME. Metodologia científica. 5. ed. São Paulo: Atlas; 2008.

11. Fontanella BJB; Luchesi BM; Saidel MGB; Ricas J; Turato ER; Melo DG. Amostragem em pesquisas qualitativas: proposta de procedimentos para constatar saturação teórica. cad. Saúde pública [internet] 2011 Fev; [cited 2014 oct 17]; 27(2): 389-394. Available from: www.scielo.br/pdf/esp/ v27n2/20.pdf.

12. Bardin, L. Análise de Conteúdo. 3. ed. Lisboa: Coleções 70; 2004.

13. Conselho Nacional de Saúde (Brasil). Resolução n 466, de 12 de dezembro de 2012, 2012 [citado 2014 set 23 ]. Available from: http:// bvsms.saude.gov.br/bvs/saudelegis/cns/2013/ res0466_12_12_2012.html

14. Scochi CGS, Brunherotti MR, Fonseca LMM, Nogueira FS, Vasconcelos MGL, Leite AM. Lazer para mães de bebês de risco hospitalizados: análise da experiência na perspectiva dessas mulheres. Rev Latino-Am Enferm. [internet] 2004 set./out Jun; [cited 2014 set 23 ]; 12 (5): 727-735. Available from: http://www.scielo.br/pdf/rlae/v12n5/ v12n5a05.pdf.

15. Gomes NS, Teixeira JBA, Barichello E. Cuidados ao recém-nascido em fototerapia: o conhecimento da equipe de enfermagem. Rev. Eletr. Enf. [internet] 2010 abr/jun; [cited 2013 nov 15]; 12(2): 337- 
41. Available from: http://dx.doi.org/10.5216/ree. v12i2.6507.

16. Souza NL, Araujo ACPF, Costa ICC, Carvalho JBL, Silva MLC. Representações de mães sobre hospitalização do filho prematuro. Rev. Bras. Enferm. [internet] 2009 set./out; [citado 2014 nov 15]; 62(5): 729-33. Available from: http://www.scielo. $\mathrm{br} / \mathrm{pdf} / \mathrm{reben} / \mathrm{v62n5/13.pdf}$.

17. Santos $I M M$, Rodrigues VA. A (des) informação das mães sobre a fototerapia - uma contribuição para a enfermagem. Rev. Soc. Bras. Enferm. Ped. [internet] 2007 jul; [cited 2013 nov 15] 7(1):25-32. Available from: http://www.sobep.org.br/revista/ images/stories/pdf-revista/vol7-n1/v.7_n.1-art3. pesq-a-desinformacao-das-maes-sobre-a-fototerapia.pdf.

18. Cechetto FH, Zen NL. Assistência de enfermagem à familia em unidade de tratamento intensivo neonatal: um estudo de revisão da literatura. Rev. Soc. Bras. Enferm. Ped. [internet] 2008 dez; [cited 2013 nov 15] 8 (2): 83-89. Available from: http://www.sobep.org.br/revista/images/stories/ pdf-revista/vol8-n2/v.8_n.2-art4.revi-assistencia-de-enfermagem-a-familia-em-uti-neonatal.pdf.

19. Oliveira T, Simões SMF. Communication faces in the practice of nursing. OBJN. [internet] 2010 nov; [cited 2015 jul 28] 9(2):1-8. Available from: http:// www.objnursing.uff.br/index.php/nursing/article/view/j.1676-4285.2010.3116/698.

20. Neto JAS; Rodrigues BMRD. Tecnologia como fundamento do cuidado em neonatologia. Texto contexto enferm. [internet] 2010 abr-jun;[cited 2015 jan 2 ]; 19(2): 372-7. Available from: http:// www.scielo.br/pdf/tce/v19n2/20.pdf.

21. Molina RCM, Fonseca EL, Waidman MAP, Marcon SS. A percepção da família sobre sua presença em uma Unidade de Terapia Intensiva Pediátrica e Neonatal. Rev. Esc. Enf. USP. [internet] 2009; [cited
2014 oct 2 ]; 43 (3): 630-38. Available from: http:// www.scielo.br/pdf/reeusp/v43n3/a19v43n3.pdf.

22. Pinho L, Santos SMA. Fragilities and potentialities in the humanization attendance process in the intensive care unit: a qualitative and dialectic based-study. OBJN. [internet] 2007 apr; [cited 2015 jul 28] 6(1):1-9. Available from: http://www. objnursing.uff.br/index.php/nursing/article/ view/853/178

Todos os autores participaram das fases dessa publicação em uma ou mais etapas a seguir, de acordo com as recomendações do International Committe of Medical Journal Editors (ICMJE, 2013): (a) participação substancial na concepção ou confecção do manuscrito ou da coleta, análise ou interpretação dos dados; (b) elaboração do trabalho ou realização de revisão crítica do conteúdo intelectual; (c) aprovação da versão submetida. Todos os autores declaram para os devidos fins que são de suas responsabilidades o conteúdo relacionado a todos os aspectos do manuscrito submetido ao OBJN. Garantem que as questões relacionadas com a exatidão ou integridade de qualquer parte do artigo foram devidamente investigadas e resolvidas. Eximindo, portanto o OBJN de qualquer participação solidária em eventuais imbróglios sobre a materia em apreço. Todos os autores declaram que não possuem conflito de interesses, seja de ordem financeira ou de relacionamento, que influencie a redação e/ou interpretação dos achados. Essa declaração foi assinada digitalmente por todos os autores conforme recomendação do ICMJE, cujo modelo está disponível em http://www. objnursing.uff.br/normas/DUDE_final_13-06-2013.pdf

Recebido: $14 / 09 / 2015$

Revisado: 27/04/2016

Aprovado: 05/05/2016 